\title{
Investigation of risk factors affecting injuries in reclining seat under frontal impact
}

\section{Liang Tang* and Jiajia Zheng*}

School of Technology,

Beijing Forestry University,

Haidian, Beijing 100083, China

Email: happyliang@bjfu.edu.cn

Email: zhengjiajia@bjfu.edu.cn

*Corresponding authors

\section{Qing Zhou}

State Key Lab of Automotive Safety and Energy,

Tsinghua University,

Haidian, Beijing 100084, China

Email: zhouqing@tsinghua.edu.cn

\begin{abstract}
In autonomous vehicles, passengers often recline their seatbacks for a more comfortable posture. Such a reclined posture greatly increases risk of submarining and other injury concerns due to the unfavourable geometrical configuration of occupant, seat and seatbelt. In this paper, numerous simulations with a modified computational dummy model are proposed to analyse effects of various occupant restraint systems in frontal impact, including seatbelt, pretensioner, load limiter, locking tongue, airbag, knee bolster and so on. After the sensitivity analyses, four concepts for designing anti-submarining countermeasures are proposed: (1) increase the lap belt-topelvis friction coefficient; (2) reduce the shoulder belt force along with the use of the locking tongue; (3) increase the lap belt angle; (4) reduce the $H$ point forward and downward displacement. Sled tests with anti-submarining countermeasures were conducted to verify the effectiveness of the anti-submarining concepts for reclining seats. Four anti-submarining countermeasures are suggested to prevent the submarining with no other auxiliary hurts: load limiter plus locking tongue, anchor pretensioners plus antisubmarining bar, seat cushion airbag, and retractor plus buckle pretensioner. This paper could give better understanding of submarining mechanism and eligible vehicle design.
\end{abstract}

Keywords: reclining seat; frontal impact; anti-submarining countermeasures; occupant restraint system; autonomous vehicle.

Reference to this paper should be made as follows: Tang, L., Zheng, J. and Zhou, Q. (2020) 'Investigation of risk factors affecting injuries in reclining seat under frontal impact', Int. J. Vehicle Safety, Vol. 11, No. 3, pp.247-274. 


\section{Introduction}

Highly automated cars are expected to be the tendency of the future vehicle industry. A qualitative study by Jorlöv et al. (2017) has shown that occupants in advanced automated vehicles will be more frequently seated in a reclined posture (e.g., $45-60^{\circ}$ from vertical). Reclined passengers involved in frontal crashes exhibit different biomechanical and injury responses in Motor Vehicle Crashes (MVC) than normally-seated passengers.

Reclined posture may result in the kinematic phenomenon known as submarining, in which the occupant slides underneath the lap belt and the lap belt deforms the abdomen (Tang and Liu, 2012). Plenty of research has been conducted on such phenomenon which may severely injure occupants during the collision accident. Some scholars reported that tendency of submarining was related to seat cushion, seating posture, passenger body, body position, crash speed, vehicle inner environment and occupant restraint systems. Nakane et al. (2015) showed that hard seat cushion behaved better in limiting forward and downward displacement of pelvis to reduce submarining tendency. Passengers in upright seat posture were difficult to submarine (Horsch and Hering, 1989). However, it was easier for small size occupants to submarine in reclining seat or a slouch position, and with collision speed increasing, submarining would be more likely to occur (Rouhana et al., 1989). Besides, the dummies' features, including dummy type, pelvis shape, lumbar spine stiffness, were related to tendency of submarining (Lundell et al., 1981; Song et al., 1993; Uriot et al., 2006; Couturier et al., 2007). However, no previous research has figured out the mechanism of submarining clearly.

According to some research on real collision accident, studies of crash data have suggested that reclined occupants have greater mortality in MVC than normally seated occupants (Dissanaike et al., 2008) and that they can be severely injured even in lowspeed crashes (Richards et al., 2006). Although sitting in a reclined posture was expected to increase occupant's risk of submarining in a crash, most studies examining PMHS submarining have positioned the subject in a posture that was similar to the standard driving posture (Luet et al., 2012).

Meanwhile, in order to decrease such kind of injury as much as possible, many scholars have researched on countermeasures to reduce the submarining tendency. Ji et al. (2017) found that submarining tendency could be decreased with knee bolster in reclining seat. Poplin et al. (2015) indicated the importance of initial lap belt fit and engagement of the lap belt on the pelvis during the frontal impact accident. The lap belt fit was associated with the location of lap belt (O'Connor and Rao, 1990), lap belt to pelvis angle (Couturier et al., 2007; Leung et al., 1981; Uriot et al., 2015a), the relationship between lap belt and shoulder belt, the lap belt shape and so on. The correct position of shoulder belt and lap belt has been stipulated respectively by regulations such as: FMVSS208, FMVSS 210, SAE J383 and ECE R14, although exhibiting subtle difference among them. Separating lap belt and shoulder belt (Horsch and Hering, 1989), which eliminated the tendency of lap belt being upward by shoulder belt, could reduce tendency of submarining. Besides, symmetrical lap belt shapes (Pywell, 1993), ensuring the forces of lap belt on both sides equally, could also prevent occupant from unilateral submarining. Adding load limiter and pretensioner to the occupant restraint system 
(Uriot et al., 2015a; Richard et al., 2015; Uriot et al., 2015b) and the combination of load limiter, airbag and pretensioner (Uriot et al., 2015a, 2015b) could also prevent submarining. Some research has been performed on the properties of the seat as well. Cantilever seat pan could increase risk of submarining (Thorbole, 2015). Preventing penetration motion of the pelvis into the seat cushion (Baudrit et al., 2005) and increasing seat cushion stiffness (Tang and Liu, 2012; Lundell et al., 1981; Song et al., 1993; Adomeit and Heger, 1975; Adomeit, 1979; Lövsund et al., 1993; Laporte, 2006; Faure et al., 2007; Beck et al., 2011) could decrease risk of submarining. Wiechel and Bolte (2006) had found that changing seat cushion angle could prevent submarining in reclining seat, while their tests were performed with rigid seat which was not appropriate for real conditions. Then, a study performed with real seat indicated that changing seat cushion angle could not prevent submarining (Tang and Liu, 2012).

However, most of the previous studies above focused on how to prevent submarining tendency in upright seat but not in reclining seat except for some studies which aim at addressing spacecraft and military applications. For example, Salzar et al. (2009) examined the response of three reclined PMHS and Hybrid III ATDs to short-duration $z$-axis loading meant to represent loading from an aircraft ejection seat. Additionally, Damon et al. (2010) subjected two supine, male PMHS to 2 ejection tests and reported spinal kinematics and injuries. No data are available for reclined PMHS kinematic and injury response in horizontal impacts relevant to MVC. There are lack of researches concerning occupant protection in reclining seat under frontal impact.

Thus, studies on the submarining mechanism, propose effective anti-submarining countermeasures and injury response of passengers seated in alternative postures under consideration for autonomous vehicles are therefore critically needed to develop appropriate injury assessment tools and safety systems.

\section{Methods}

\subsection{Dummy model modification and validation}

\subsubsection{Model modifications}

It is known that a small female occupant is easier to submarine in frontal impact. Therefore, a First Technology Safety Systems (FTSS) HIII 5th percentile female dummy model was chosen as the baseline model in this study. However, in the standard dummy model the flesh part of the hip and thigh was modelled as a seated occupant in a single piece, and this fixed shape one-piece flesh design constrained the rotational freedom of the pelvis and made the dummy model unsuitable for submarining analysis in reclining seat. A more human-body-like non-linear finite-element dummy model proposed by Tang et al. (2010) can recline in a reclining seat, based on the FTSS HIII 5th-percentile female dummy model, as shown in Figure 1. 
Figure 1 Standard and modified computational model. (a) Standard hip and thigh (b) Modified hip and thigh (c) Modified whole dummy model

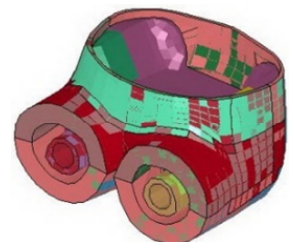

(a)

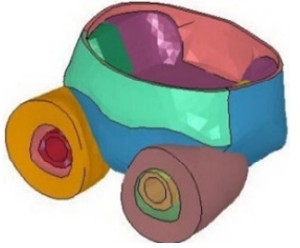

(b)

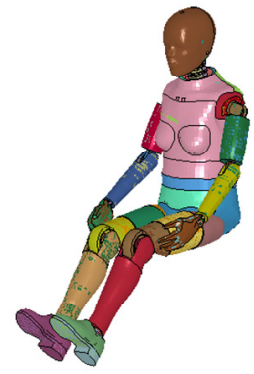

(c)

\subsubsection{Model validation}

For the standard dummy with one-piece pelvis design (see Figure 2(a)) cannot be adjusted to fit the reclining seatback angle like human beings, thus a pedestrian pelvis adaptor (Figure 2(b)) was added to our HIII 5th female dummy acquired from DETON. The HIII dummy with the pedestrian pelvis adaptor was more in line with human beings when fitting into a reclined seatback angle (Figure 2(c)).

Figure 2 Standard and modified dummy. (a) Standard pelvis (one piece) (b) Pedestrian pelvis adaptor (three pieces) (c) Modified dummy

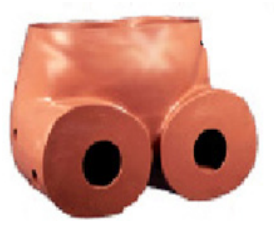

(a)

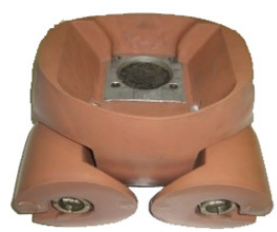

(b)

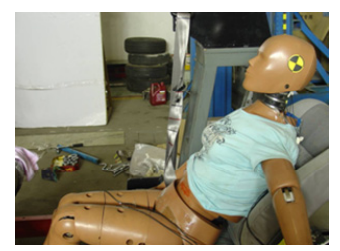

(c)

The sensors in the dummy can output impact injury data, including the head and chest acceleration, the neck force and moment, the femur force, the chest compression, the iliac wing force and moment, and the belt force. The iliac wing load cell was only available on the standard pelvis because there was no space for mounting it on the pedestrian pelvis adaptor.

In simulation, the modified dummy model was restrained by the seatbelt to the seat and the seat was fixed to the rigid floor. A $48 \mathrm{~km} / \mathrm{h}$ generic pulse of frontal impact prescribed by General Motors (GM) was applied to the model. The configurations for the sled test were consistent with those in simulation. 
Observed from the high-speed video (see Figure 3), the lap belt was maintained on the iliac wing and never moves into the abdomen during the impact, indicating no submarining occurrence in upright seating condition. This was consistent with the simulation results. The injury time history of the comparisons between test and simulation are shown in Figure 4, indicating the effectivity of the combined seat/belt/ dummy model for the good agreement between the sled and the simulation.

Figure 3 Comparisons of the model kinematics between sled test and simulation. (a) High speed video of the sled test (b) Simulation animation

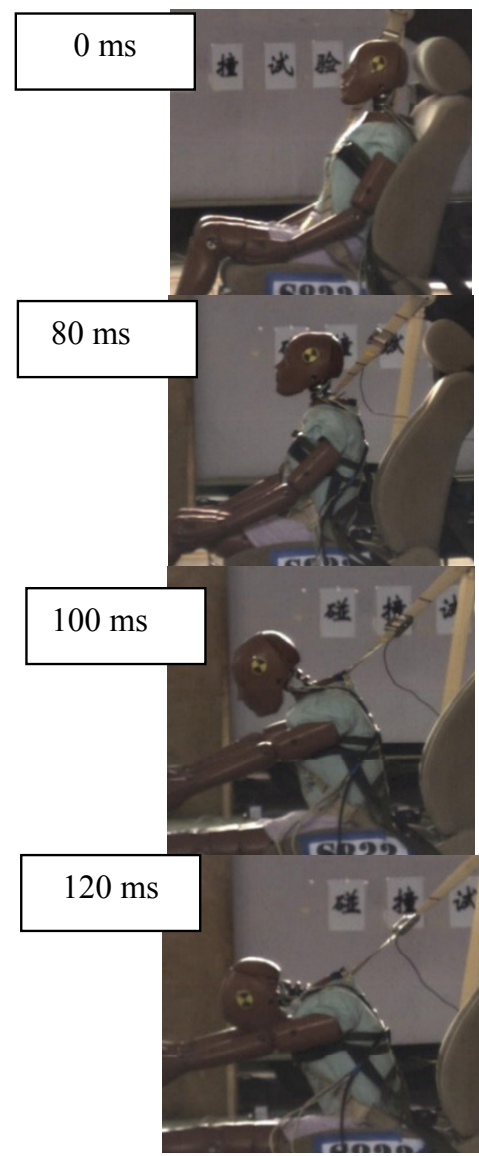

(a)
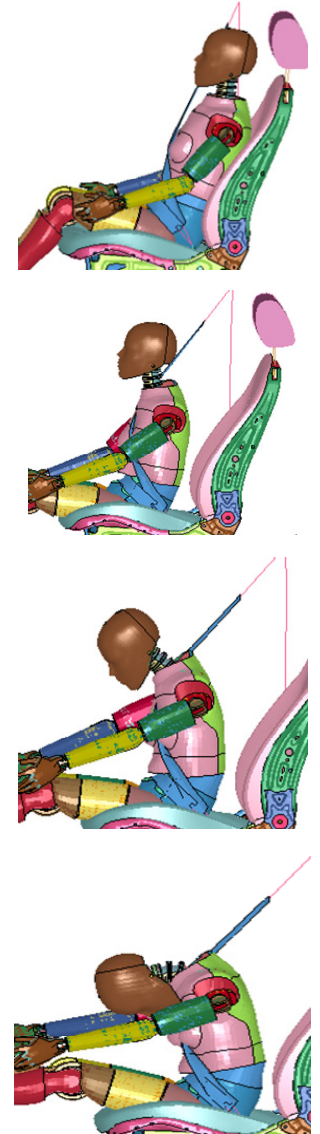

(b) 
Figure 4 Comparisons of the kinematics between test and simulation. (a) Head acceleration (b) Chest deflection (c) Chest acceleration (c) Shoulder belt force

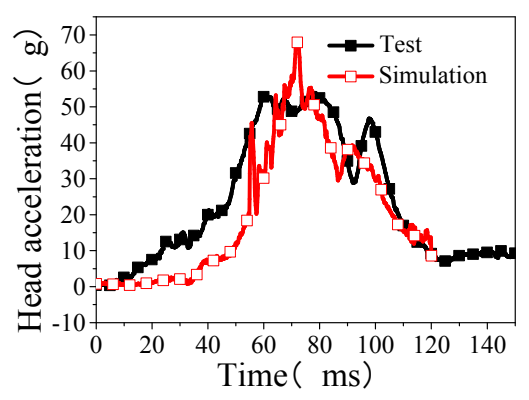

(a)

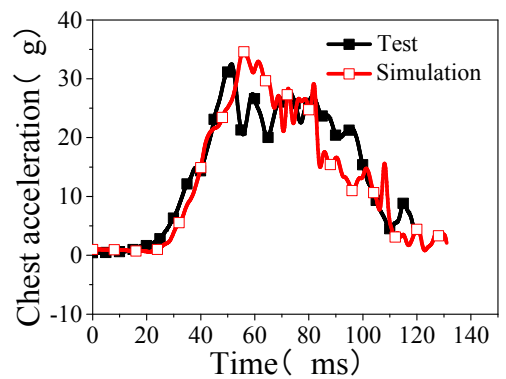

(c)

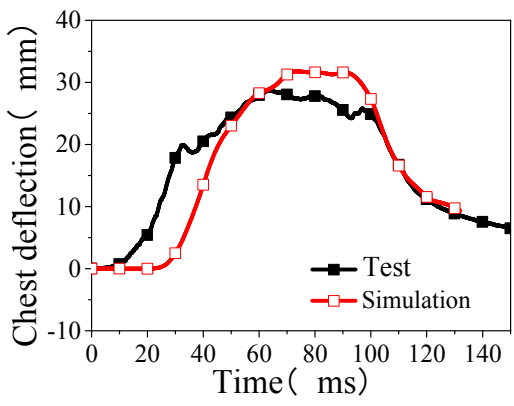

(b)

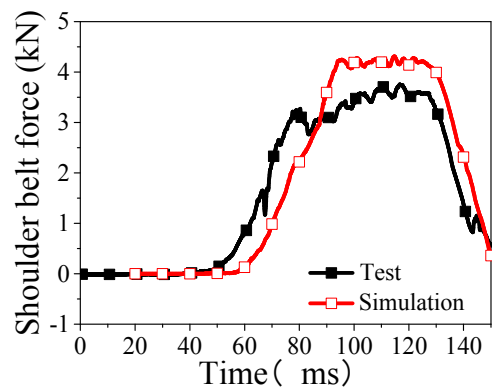

(d)

\subsection{Parametric study}

Based on the validated model, numerous simulations were performed to investigate the risk factors affecting submarining tendency in reclining seat. A submarining tendency indicator BOP (belt of position), representing relative lap belt position to the pelvis, proposed by Tang and Zhou (2009), was used in this paper. When the BOP value was greater than zero, it can predict submarining occurrence. BOP value should be calculated in left side and right side of the lap belt, respectively. Larger BOP value implies greater submarining tendency. Magnitudes of different levels for the selected factors for parametric study were listed in Table 1. Peak BOP value in the first four factors were used to compare the submarining tendency, while for other cases, the simulation animations were used to monitor the submarining occurrence. 
Table 1 Summary of the numerical simulations for parametric study

\begin{tabular}{lcccccc}
\hline Factors considered & Case 1 & Case 2 & Case 3 & Case 4 & BOP & $\begin{array}{c}\text { Simulation } \\
\text { animation }\end{array}$ \\
\hline LB angle $\beta\left(^{\circ}\right)$ & 45 & 52 & 73 & $/$ & $\sqrt{ }$ & \\
$\begin{array}{l}\text { LB to pelvis friction } \\
\text { coefficient }\end{array}$ & 0.2 & 0.3 & 0.4 & 0.5 & $\sqrt{ }$ & \\
Pretensioner & No & $\mathrm{RP}^{1}$ & $\mathrm{BP}^{2}$ & $\mathrm{AP}^{3}$ & $\sqrt{ }$ & \\
Pretensioners & $\mathrm{RP}+\mathrm{AP}$ & $\mathrm{BP}+\mathrm{AP}$ & $\mathrm{RP}+\mathrm{BP}$ & $/$ & $\sqrt{ }$ & \\
$\mathrm{LL}^{4}+\mathrm{LT}^{5}$ & $\mathrm{No}$ & $\mathrm{L}$ & $\mathrm{L}+\mathrm{LT}$ & $/$ & & $\sqrt{ }$ \\
Pretensioner $+\mathrm{LT}$ & $\mathrm{RP}+\mathrm{LT}$ & $\mathrm{BP}+\mathrm{LT}$ & $\mathrm{AP}+\mathrm{LT}$ & $/$ & & $\sqrt{ }$ \\
$\begin{array}{l}\text { D-ring forward } \\
\text { Seat cushion }\end{array}$ & $\mathrm{No}$ & $\mathrm{DF}$ & $\mathrm{DF}+\mathrm{LT}$ & $/$ & & $\sqrt{ }$ \\
structure & Design S & Design $\mathrm{H}^{8}$ & $/$ & $/$ & & $\sqrt{ }$ \\
$\begin{array}{l}\text { Seat cushion airbag } \\
\text { Knee bolster }\end{array}$ & Without & With & $/$ & $/$ & & $\sqrt{ }$ \\
\hline
\end{tabular}

Note: ${ }^{1} \mathrm{RP}$ : retractor pretensioner; ${ }^{2} \mathrm{BP}$ : buckle pretensioner; ${ }^{3} \mathrm{AP}$ : anchor pretensioner; ${ }^{4} \mathrm{LL}$ : load limiter; ${ }^{5} \mathrm{LT}$ : locking tongue; ${ }^{6} \mathrm{DF}$ : D-ring forward; ${ }^{7} \mathrm{~S}$ : soft front edge seat; ${ }^{8} \mathrm{H}$ : hard front edge seat.

\subsection{Effectiveness of anti-submarining countermeasures}

\subsubsection{Computational study}

Figure 5 details the sled test setup for front row passenger. The passenger airbag, knee bolster and foot panel are included in the model for countermeasure development. Based on the sensitivity analyses, eight anti-submarining countermeasures were proposed to reduce the risk of submarining, as shown in Table 2.

Figure 5 CAE model of the validation simulations

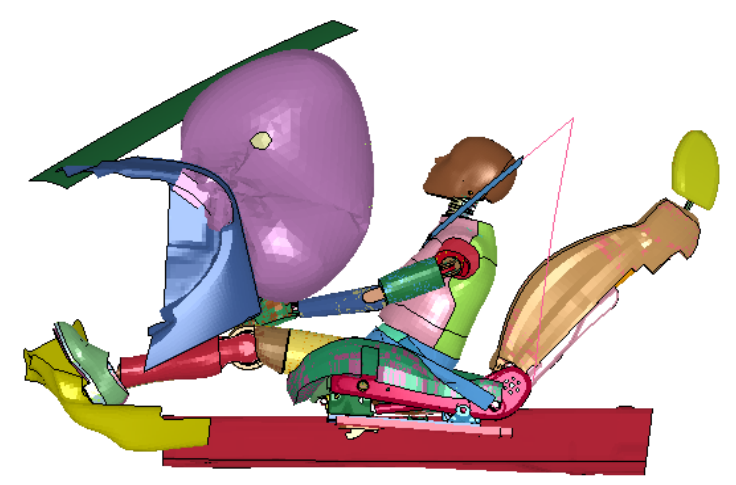


Table 2 The matrix of the simulations with different countermeasures

\begin{tabular}{cccccc}
\hline Test No. & Seatback angle & Countermeasures & Peak BOP & Peak $B O P_{R}$ & Submarining \\
\hline A & 23.5 & No & -0.90 & -0.88 & No \\
B & 50 & No & 0.77 & 1.13 & Yes \\
C & 50 & Load limiter 2.2kN+ LT ${ }^{1}$ & -0.87 & -0.57 & No \\
D & 50 & Seat cushion airbag & -0.96 & -0.86 & No \\
E & 50 & Anti-submarining bar + LT & -0.58 & -0.79 & No \\
F & 50 & Anti-submarining bar $+\mathrm{RP}^{2}$ & -0.90 & -0.88 & No \\
G & 50 & RP $+\mathrm{BP}^{3}$ & -0.77 & -0.91 & No \\
H & 50 & LB $^{4}$ anchorage 70mm forward & -0.86 & -0.95 & No \\
I & 50 & ${ }^{5} \mathrm{AP}+\mathrm{LT}$ & -0.75 & -0.73 & No \\
J & 50 & D-ring 280mm forward + LT & -0.87 & -0.71 & No \\
\hline
\end{tabular}

Note: $\quad{ }^{1} \mathrm{LT}$ : locking tongue; ${ }^{2} \mathrm{RP}$ : retractor pretensioner; ${ }^{3} \mathrm{BP}$ : buckle pretensioner;

${ }^{4} \mathrm{LB}$ : lap belt; ${ }^{5} \mathrm{AP}$ : anchor pretensioner.

\subsubsection{Sled tests verification}

CAD model of the sled is shown in Figure 6(a). In the sled environment, the seatbelt D-ring was designed to be adjustable in both horizontal and vertical directions in order to investigate effect of D-ring location, as shown in Figure 6(b). Seatbelt anchor and buckle locations, which determined the lap belt angle, can also be adjusted in the horizontal direction, as shown in Figure 6(c). Knee bolster location, which was also a key parameter to dominate the submarining tendency, was designed to be adjustable as well, as shown in Figure 6(d). Seat, seatbelt and knee bolster were replaced with a new set after each test.

Figure 6 Details for the sled tests (a) CAD model (b) Adjustable D-ring (c) Adjustable lower anchorage (d) Knee bolster

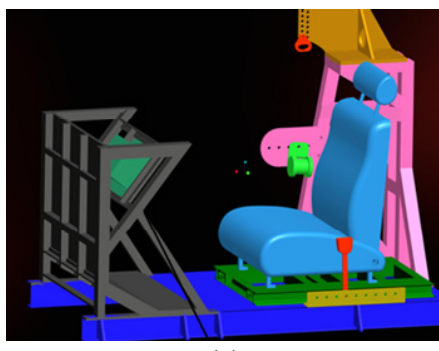

(a)

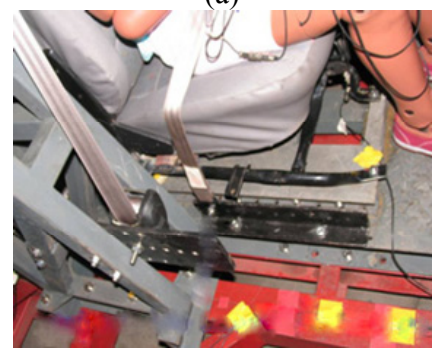

(c)

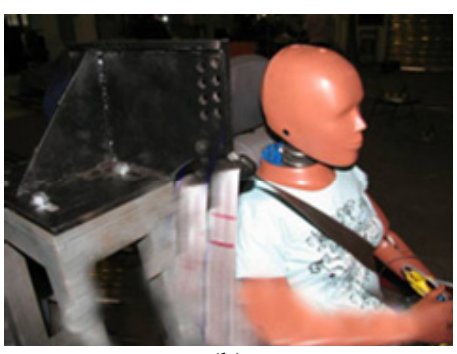

(b)

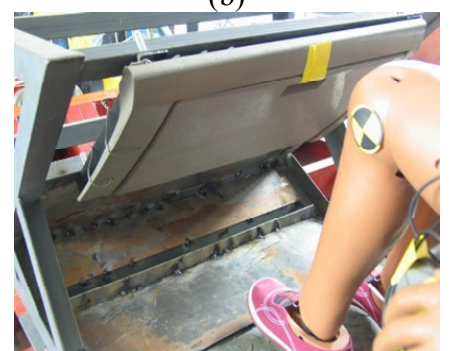

(d) 
The standard dummy with the pedestrian pelvis adaptor, which can fit into a large reclined seatback angle, is used to study the effectiveness of the countermeasures for anti-submarining in reclining seat $(48 \mathrm{~km} / \mathrm{h})$. The sled tests matrix is shown in the Table 3. The seat cushion angle was $12^{\circ}$ in all sled tests.

Table 3 Sled tests matrix

\begin{tabular}{cclc}
\hline Test No. & Seatback angle & \multicolumn{1}{c}{ Countermeasures } & Submarining \\
\hline $1(\mathrm{~S} 815)$ & $45^{\circ}$ & Baseline (Wiechel and Bolte, 2006) & Yes \\
$2(\mathrm{~S} 816)$ & $22^{\circ}$ & Baseline (upright) & No \\
$3(\mathrm{~S} 818)$ & $45^{\circ}$ & Anti-submarining bar $+\mathrm{LT}^{1}$ & No \\
$4(\mathrm{~S} 819)$ & $45^{\circ}$ & Shoulder belt slack $+\mathrm{LT}$ & No \\
$5(\mathrm{~S} 820)$ & $45^{\circ}$ & Anchor and buckle forward $+\mathrm{LT}$ & No \\
$6(\mathrm{~S} 821)$ & $45^{\circ}$ & Knee bolster backward $+\mathrm{LT}$ & No \\
\hline
\end{tabular}

Note: $\quad{ }^{1}$ LT: Locking tongue.

Sled test setup for four cases with anti-submarining countermeasures is shown in Figure 7. Configurations for tests S815 and S816 without countermeasure are shown in Figure 7(a) and Figure 7(b), respectively. In S818, anti-submarining bar and Locking Tongue (LT) were used (Figure 7(c)). The locking tongue used on the buckle side can prevent the shoulder belt moving into the lap belt webbing and allow the belt webbing sliding in the opposite direction. In S818, the bar positioned $146 \mathrm{~mm}$ to the front edge of the frame, was welded on the cushion frame. In S819, sufficient shoulder belt slack was added to ensure that the upper torso achieves more forward excursion during the impact. To ensure the correct loading path of the shoulder belt with the belt slack, the shoulder belt was affixed on the thorax (Figure 7(d)). In S820, the seatbelt lower anchorage and buckle was positioned $160 \mathrm{~mm}$ forward to increase the lap belt angle and reduce submarining tendency with locking tongue used (Figure 7(e)). In S821, the knee bolster was moved $300 \mathrm{~mm}$ backward to prevent femur forward displacement during the impact. The locking tongue was also used in the test (Figure 7(f)).

Figure 7 Setup for six sled tests w/ or w/o anti-submarining countermeasures. (a) Baseline (Wiechel and Bolte, 2006) (b) Baseline (upright) (c) Anti-submarining bar (d) Shoulder belt slack (e) Anchor and buckle forward (f) Knee bolster backward

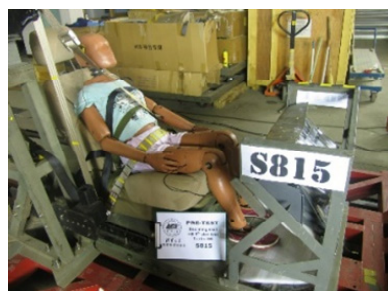

(a)

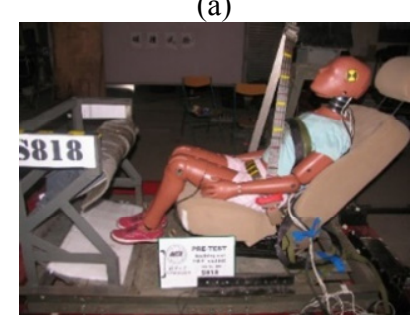

(c)

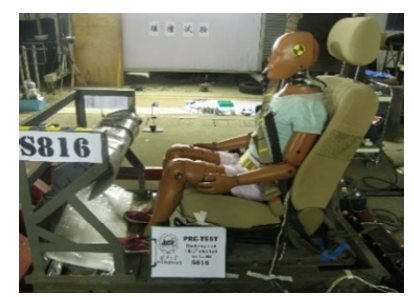

(b)

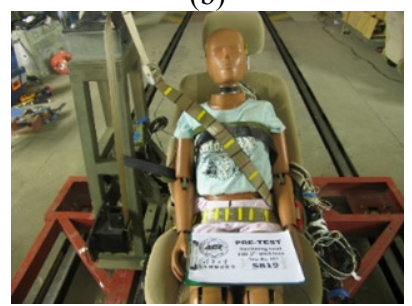

(d) 
Figure 7 Setup for six sled tests $w /$ or w/o anti-submarining countermeasures. (a) Baseline (Wiechel and Bolte, 2006) (b) Baseline (upright) (c) Anti-submarining bar (d) Shoulder belt slack (e) Anchor and buckle forward (f) Knee bolster backward (continued)

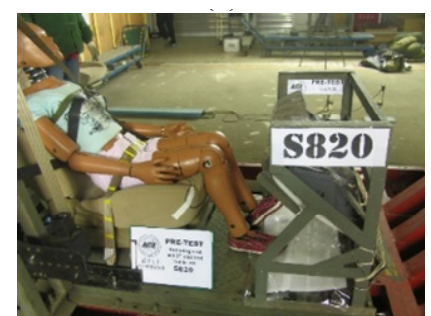

(e)

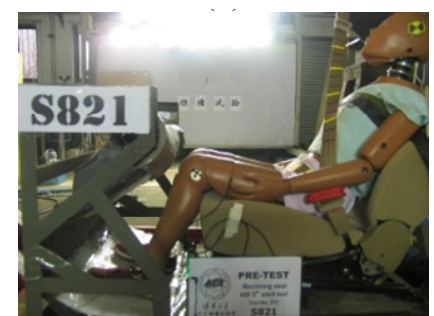

(f)

\section{Results}

\subsection{Effects of various factors on submarining tendency in parametric study}

Effects of lap belt angle on submarining tendency was investigated by changing the lower anchorage positions and the left and right lap belt angels to horizontal $\left(45^{\circ}, 52^{\circ}\right.$, $73^{\circ}$ ) were selected in the MVSS210 corridor. The BOP time history of different lap belt angles is shown in Figure 8(a). Larger lap belt angle implies greater threshold for submarining. The lap belt angle determines the critical belt-to-pelvis angle at which the belt slips off the pelvis, and the lap belt angle determines its moment direction about the pelvis centre of gravity.

The coefficient of the lap belt-to-pelvis friction is varied from 0.2 to 0.5 to study its influence on submarining tendency. It can be seen in Figure 8(b) that the BOP value decreases with the increase of the friction coefficient, implying lower risk of submarining.

Figure 8 BOP time history. (a) Lap belt angles (b) Friction of coefficient

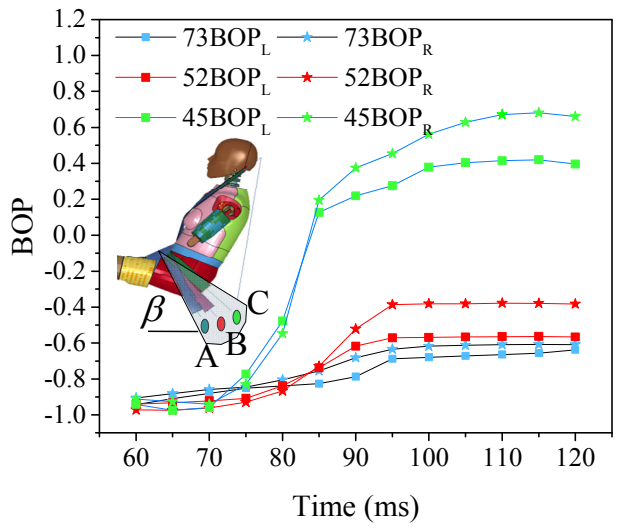

(a)

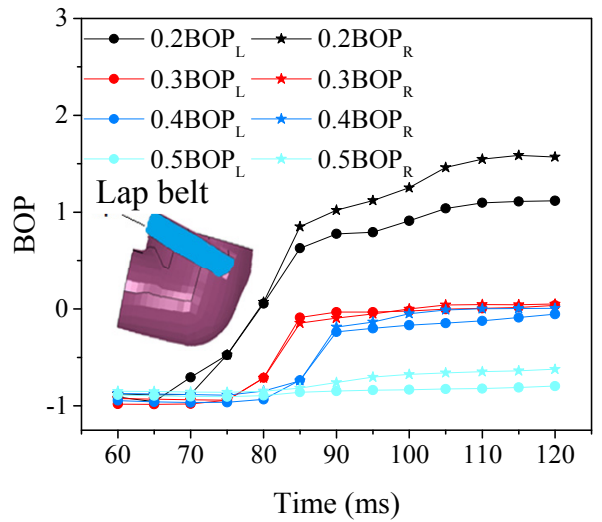

(b) 
In real world, the friction force can be increased by reducing the lap belt slack, e.g., using seatbelt pretensioners. From the viewpoint of the retractor pretensioner, the positive effect for reducing submarining tendency is that when it pulls the shoulder belt, the lap belt will move into the shoulder belt through the buckle slip ring. This will increase the belt-to-pelvis friction force, which is good for preventing submarining. The increased force in the lap belt also reduces the H-point forward movement, and thus reduces the submarining tendency. The negative effect is that it increases shoulder belt force which restrains the upper torso forward motion. For the buckle pretensioner, the good effect is that it reduces lap belt slack and increases the belt-to-pelvis friction force. The negative effect is that it also increases the shoulder belt force, which restrains the upper torso forward rotation. For the anchor pretensioner, when it pulls the lap belt, the shoulder belt may move into the lap belt. As a result, the shoulder belt force is increased and the lap belt slack may not be sufficiently reduced. Therefore, the anchor pretensioner alone is not good for reducing the submarining tendency. Let us see the simulation results for each pretensioner. Three cases are conducted with retractor pretensioner, buckle pretensioner and anchor pretensioner, respectively, as shown in Figure 9(a). The maximum stroke of these seatbelt pretensioners is $70 \mathrm{~mm}$ (the stroke for retractor pretensioner is $70 \mathrm{~mm}$. To make the pretensioners comparable, the stroke for anchor and buckle pretensioners are also set as $70 \mathrm{~mm}$ ), and their trigger time is $10 \mathrm{~ms}$ after the initial impact. These results show that in terms of the submarining tendency: Buckle_Pretensioner $<$ Retractor_Pretensioner $<$ Anchor_Pretensioner.

Based on the above analysis and results in Figure 9(b), it is recognised that the combination of retractor and buckle pretensioners has the best effect on reducing the submarining tendency.

Figure 9 Effects of pretensioner on submarining tendency. (a) Single pretensioner (b) Two pretensioners

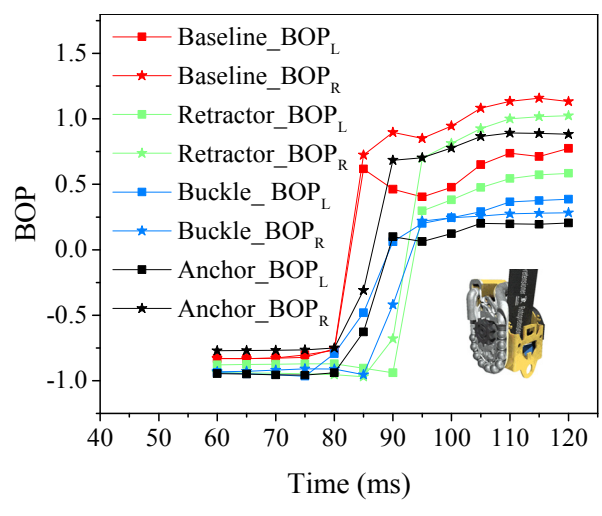

(a)

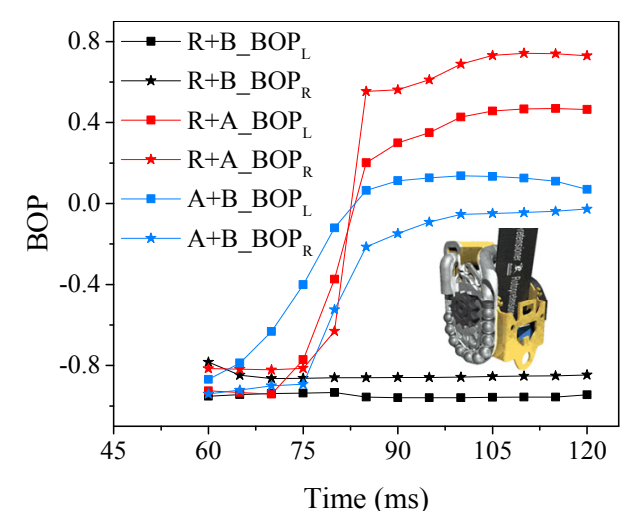

(b)

Relaxing the shoulder belt constraint can reduce submarining tendency. For the purpose we consider adding load limiter and locking tongue to the shoulder belt. Three different load conditions are shown in Figure 10. In cases A and B (see Figure 11), LS-DYNA keyword *ELEMENT_SEATBELT_SLIPRING is used to simulate the webbing movement from the shoulder belt to the lap belt and the reverse. It is seen that if the 
shoulder belt force is greater than the lap belt force, the lap belt will slip into the shoulder belt, and vice versa. In order to reduce the pelvis forward displacement and increase torso forward displacement, the shoulder belt constraint should be reduced to allow forward rotation of the upper torso. Moreover, the lap belt slack should be reduced to increase the belt-to-pelvis friction force. These countermeasure strategies may be achieved by using a seatbelt one-way locking tongue, which has a one-way moving mechanism to prevent the shoulder belt from moving into the lap belt, but allow the lap belt moving into the shoulder belt. In case C (Figure 11), we decouple the shoulder belt from the lap belt. It is essentially a two-way locking tongue. In this mechanism, both directions of the belt moving are forbidden. In summary, the purpose of using the load limiter is to reduce the shoulder belt constraint in order to have a favourable upper torso forward rotation and prevent pelvis rearward rotation, which is a strategy of reducing the submarining tendency. When reducing the shoulder belt constraint, the shoulder belt is more likely to move into the lap belt, which is not good for preventing submarining. Two-way locking tongue, decoupling the shoulder belt from the lap belt, is used to restrict the movement, and thus achieve the best effect for reducing submarining tendency.

Figure 10 Loading forces of cases with load limiter

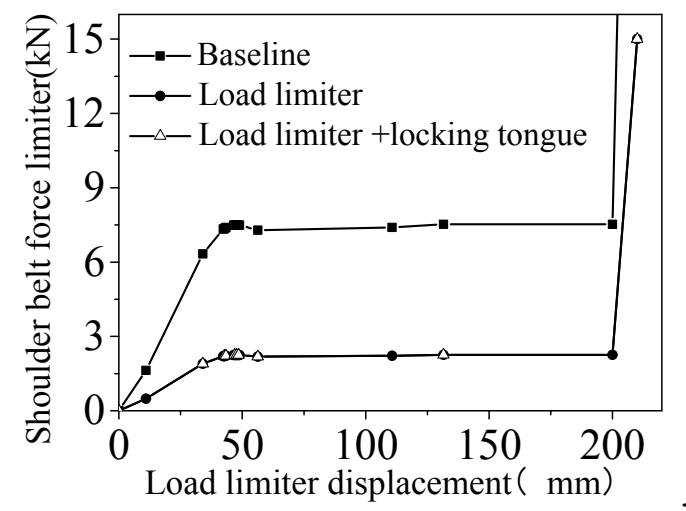

The effect of D-ring longitudinal location on submarining tendency is investigated. This is because the shoulder belt constraint in Case B is smaller than that in Case A, and thus ensures more upper torso forward rotation. In Case B, the D-ring is positioned $280 \mathrm{~mm}$ forward and the two-way locking tongue is used (see Figure 12). The animation shows that the submarining does not occur in this case. Based on the submarining mechanism, high shoulder belt restraint force is a negative factor. More forward D-ring position can reduce the shoulder belt constraint.

In frontal impact, the seat cushion mainly controls the dummy kinematics, and thus submarining sequence. Figure 13 shows two designs of the seat cushion frame. In Design A, the seat cushion frame is constructed by a steel flat pan, and in Design B, there is a bar positioned below the cushion pan, as shown in Figure 13. Based on the model shown in Figure 13, the submarining performance of Designs A and B is analysed. In both cases, the two-way locking tongue is also used to help to reduce the submarining tendency in reclining seats. 
Figure 11 Comparison of kinematics between cases (load limiter). (a) Case A-Baseline (b) Case B-Load limiter (c) Case C-Load limiter + locking tongue
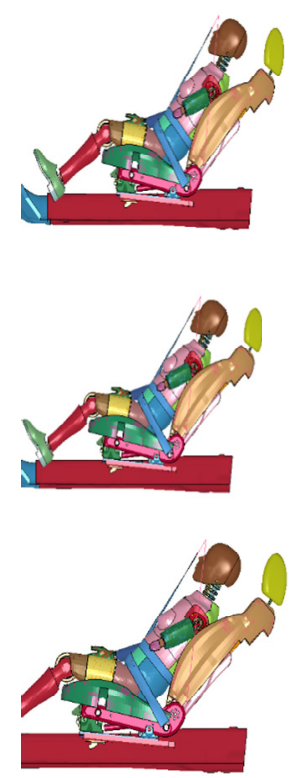

$t=0 \mathrm{~ms}$
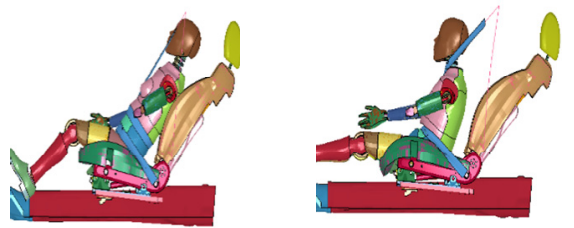

(a)

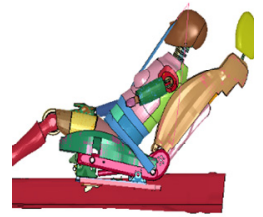

(b)
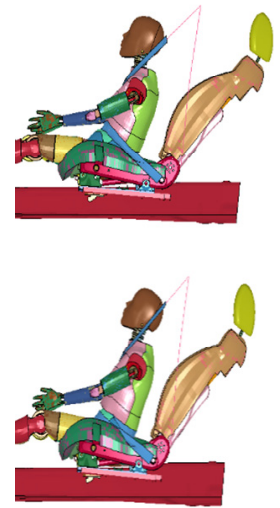

(c)

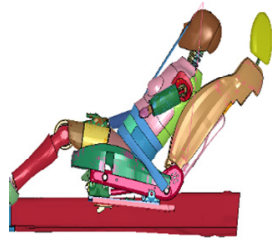

$t=50 \mathrm{~ms}$

$t=90 \mathrm{~ms}$
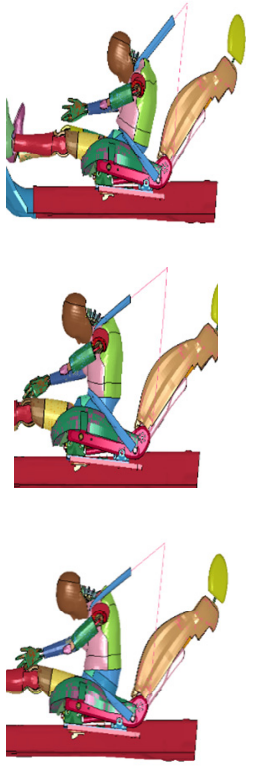

$t=130 \mathrm{~ms}$

Figure 12 Kinematics comparison of D-ring location effect. (a) Case A-Baseline (b) Case B (Forward D-ring location + two-way locking tongue)
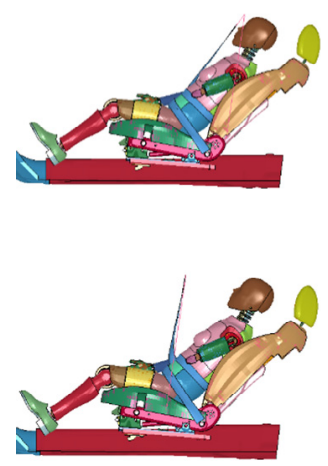

$t=0 \mathrm{~ms}$

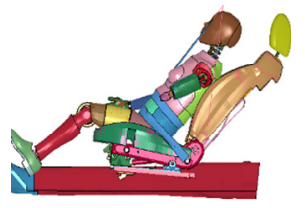

(a)

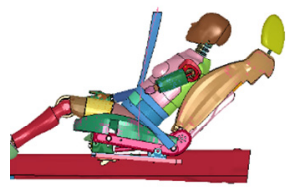

(b)
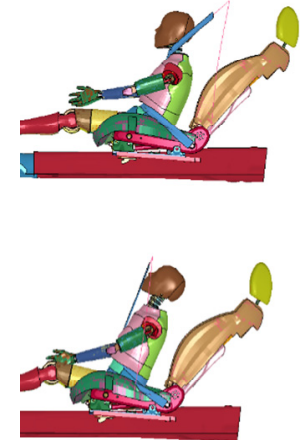

$t=90 \mathrm{~ms}$
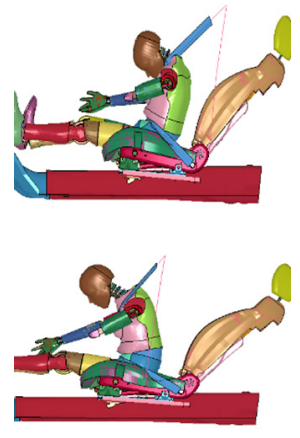

$t=130 \mathrm{~ms}$ 
Figure 13 Seat cushion structure. (a) Kinematics for Design A (b) Kinematics for Design B (Anti-submarining bar)
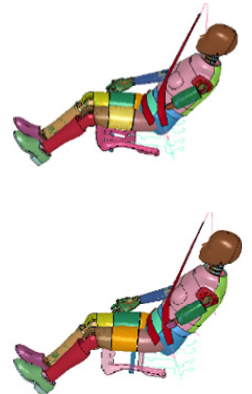

$t=0 \mathrm{~ms}$

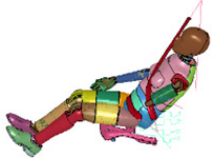

(a)

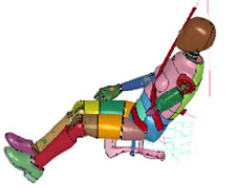

(b)
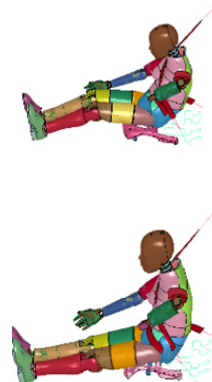

$t=100 \mathrm{~ms}$
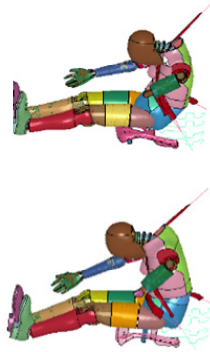

$t=130 \mathrm{~ms}$

Increasing pelvis restraint force can reduce submarining tendency. Figure 14 compares the model with (Case B) and without (Case A) seat cushion airbag. The deploy time for the cushion airbag is $30 \mathrm{~ms}$ after impact. From the dummy kinematics shown in Figure 14, at $90 \mathrm{~ms}$, in Case A, the lap belt slips off the pelvis and penetrates into the abdomen; while in Case B, during the entire impact period the lap belt maintains on the iliac wing and never moves up to the abdomen. It indicates that the submarining occurs in Case A, and does not occur in Case B. Since this was just for demonstrating the pelvis airbag effect in preventing submarining, we did not put much effort in optimising the airbag parameters.

Figure 14 Seat cushion airbag. (a) Case A-Baseline (with no seat cushion airbag) (b) Case B-With seat cushion airbag
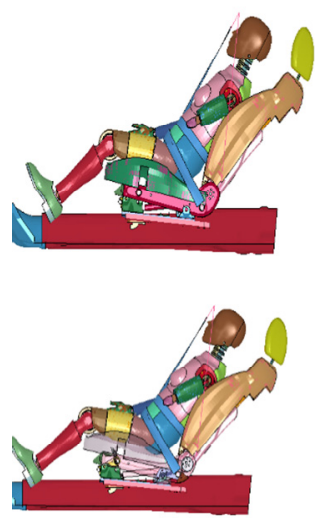

$t=0 \mathrm{~ms}$

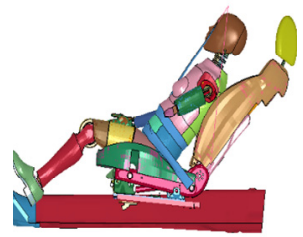

(a)

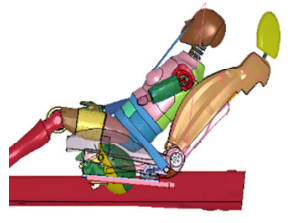

(b)
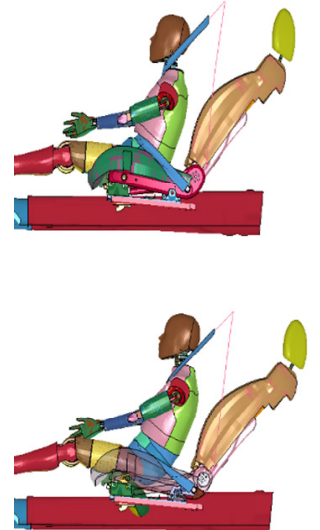

$t=90 \mathrm{~ms}$
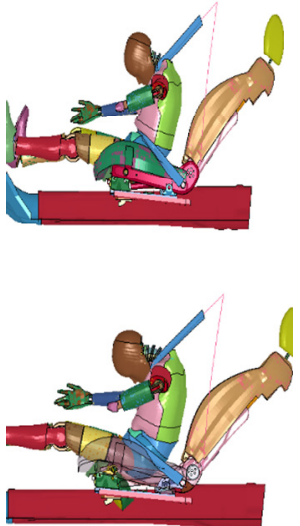

$t=130 \mathrm{~ms}$ 
Two factors, the rearward pelvic rotation and the H-point downward displacement, play critical roles in influencing submarining. As Figure 14 shown, the horizontal resisting force from the seat cushion airbag produces the moment for the forward rotation of the pelvis. The vertical resisting force reduces the H-point downward displacement, and thus reduces the relative slip between the belt and the pelvis. Using of the seat cushion airbag can reduce submarining tendency. Meanwhile, it should not induce other dangers, e.g., unacceptable force level exerted on the pelvis by the deployed cushion.

\subsection{Effect of different anti-submarining countermeasures}

Animations for the numerical simulations of different anti-submarining countermeasures were shown in Appendix. Using the submarining tendency assessment criteria, the BOP values are calculated in Figure 15 to compare the submarining tendency of these countermeasures. It is seen that no submarining occurs when using any of the countermeasures. However, because of the large travel distance of the upper torso, when the dummy engages with the restraint system, the velocity change $\Delta V$ is greater in the situation with reclining seat than that with upright seat, which could result in higher risk of head and neck injuries. Table 4 shows the values of the injury parameters required in FMVSS 208 for all the cases, and higher HIC and Nij values exhibit in the reclining seating positions. In these simulations, due to the seating posture. Although the submarining tendency can be controlled by the proposed countermeasures, the reclining posture increases the risk of head and neck injuries due to the large travel distance of the upper torso. The use of pelvis airbag and anti-submarining bar results in lower values associated with head and neck injuries.

Reclining seating positions could induce higher $\mathrm{HIC}$ and $\mathrm{Nij}$ values. It can be observed that anti-submarining countermeasures $(\mathrm{E}, \mathrm{H}, \mathrm{I}, \mathrm{J})$ can reduce the submarining but head or neck injuries was induced, only four left $(C, D, F, G)$ could reduce the submarining without any other injuries.

Figure 15 Comparisons of BOP curves of the different cases. (a) $\mathrm{BOP}_{\mathrm{L}}$ (b) $\mathrm{BOP}_{\mathrm{R}}$

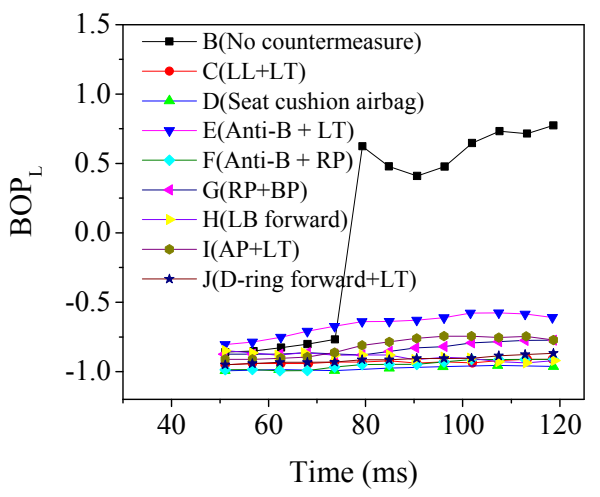

(a)

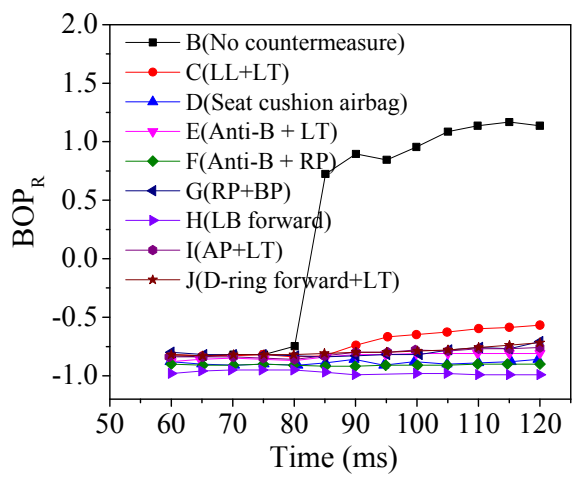

(b) 
Table 4 FMVSS 208 required injury numbers

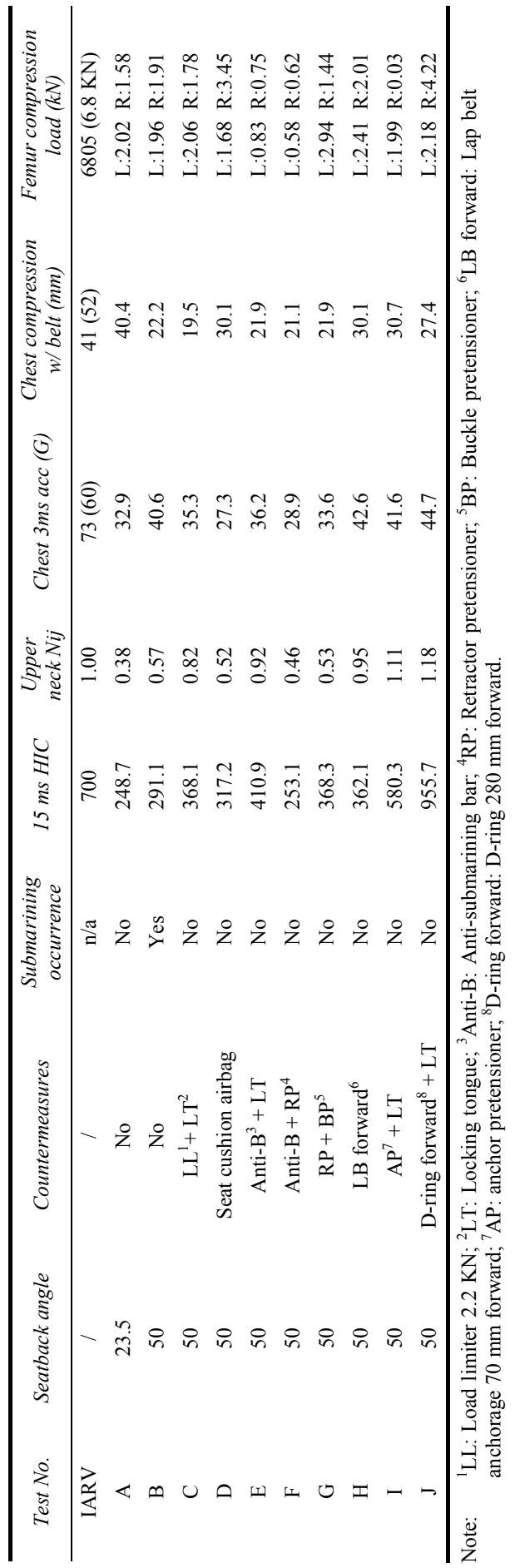




\subsection{Sled tests verification}

Observed from the high-speed video (see Figure 16(b)), during the impact, the lap belt is maintained on the iliac wing and never moves into the abdomen in sled test S816, indicating no submarining occurrence in this upright seating condition. While in sled test S815, the lap belt penetrates into the abdomen on both the buckle side and the anchor side, confirming occurrence of a bilateral submarining (Figure 16(a)).

Figure 16 Submarining sequences of six sled tests. (a) Submarining sequence of test in reclining seat (S815) (b) Submarining sequence of test in upright seat (S816) (c) Submarining sequence of test with anti-submarining bar (S818) (d) Submarining sequence of test with shoulder belt slack (S819) (e) Submarining sequence of test with anchor and buckle $160 \mathrm{~mm}$ forward (S820) (f) Submarining sequence of model in test with knee bolster $300 \mathrm{~mm}$ backward (S821)

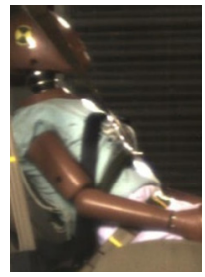

(I) $70 \mathrm{~ms}$

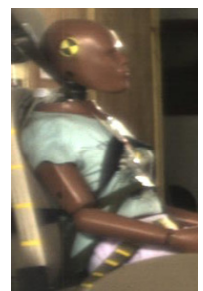

(I) $0 \mathrm{~ms}$

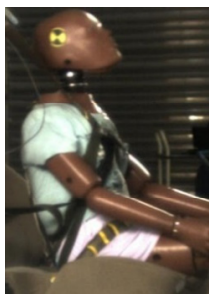

(I) $90 \mathrm{~ms}$

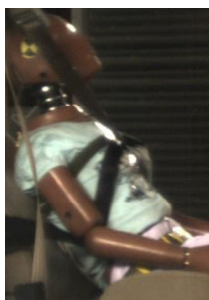

(I) $70 \mathrm{~ms}$

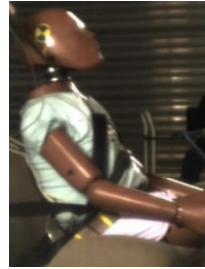

(II) $90 \mathrm{~ms}$

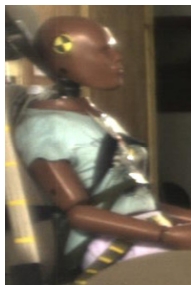

(II) $40 \mathrm{~ms}$

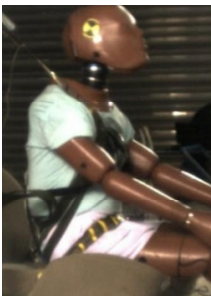

(II) $100 \mathrm{~ms}$

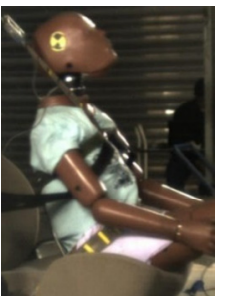

(II) $90 \mathrm{~ms}$

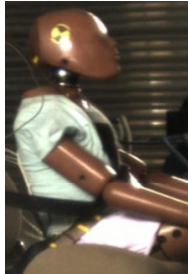

(III) $100 \mathrm{~ms}$

(a)

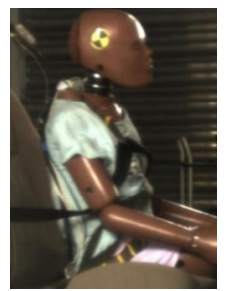

(III) $60 \mathrm{~ms}$ (b)

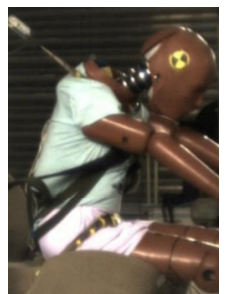

(III) $120 \mathrm{~ms}$

(c)

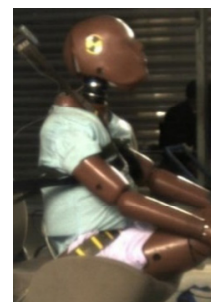

(III) $100 \mathrm{~ms}$

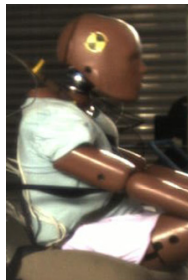

(IV) $110 \mathrm{~ms}$

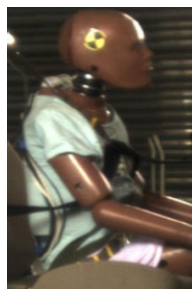

(IV) $90 \mathrm{~ms}$

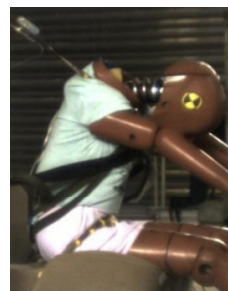

(IV) $130 \mathrm{~ms}$

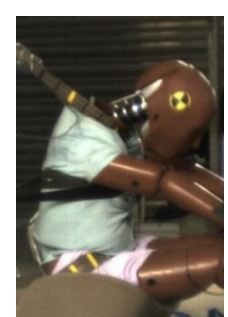

(IV) $120 \mathrm{~ms}$

(d) 
Table 5 FMVSS 208 required injury outcomes

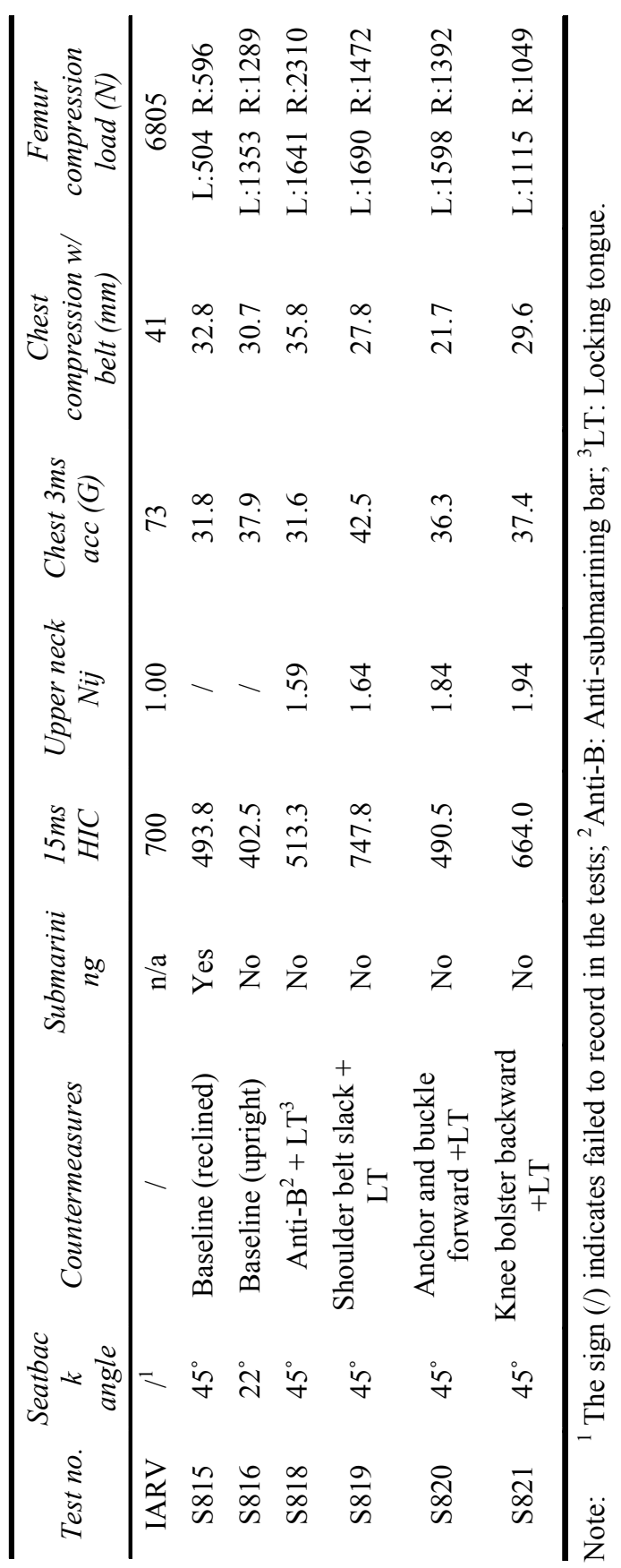


Comparing the S815 and S816 results in Table 5, it can be observed that large seatback angle not only results in high submarining risk but also increases the head, neck and chest injury numbers (except the chest compression). This is consistent with the simulation results.

S818 through S821 are the tests for the countermeasure verification for reclined seatback angle of $45^{\circ}$. The seat cushion bar and the seatbelt locking tongue are used in S818 as the countermeasures. The bar, positioned $146 \mathrm{~mm}$ to the front edge of the frame, is welded on the cushion frame (see Figure 17(a)). The locking tongue used on the buckle side can prevent the shoulder belt moving into the lap belt webbing and allow the belt webbing sliding in the opposite direction. No submarining is observed from the highspeed video of this test, demonstrating that the combination of the bar and the locking tongue can well prevent submarining, which is consistent with the conclusion obtained from the simulation study. From Table 5, it can be seen that, with this countermeasure the head and neck injury values are lower than those with other countermeasures. This is in part due to the fact that the seat cushion bar can absorb some impact energy and does not reduce any other constraint force (such as the shoulder belt and lap belt constraint). The bar is deformed by the dummy during the impact and its pre-test and post-test situations are shown in Figures 17(a) and 17(b), respectively.

Figure 17 The locking tongue and anti-submarining bar in S818. (a) Locking tongue (b) Cushion bar (pre-test) (c) Cushion bar (post-test)

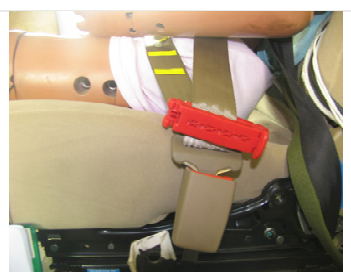

(a)

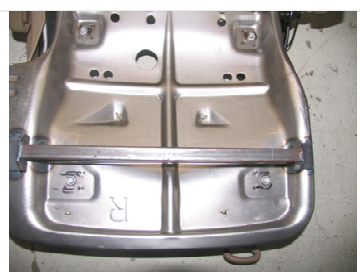

(b)

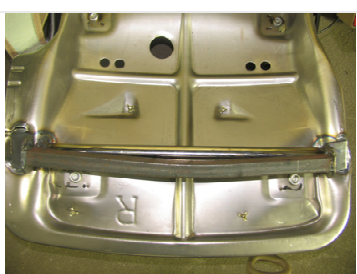

(c)

In S819, we set sufficient shoulder belt slack to ensure that the upper torso achieves more forward excursion during the impact. To ensure the correct loading path of the shoulder belt with the belt slack, the shoulder belt is affixed on the thorax as shown in Figure 7(d). No submarining is observed from the test movie, verifying the effectiveness of this countermeasure and the anti-submarining concept of reducing upper body constraint. However, reducing the upper body constraint may increase the head and neck injury (see Table 5) due to the greater velocity change when engaging with the shoulder belt.

As discussed in Sub-section 3.1, the greater the lap belt angle, the smaller the submarining tendency. So in S820, as shown in Figure 7(e), the seatbelt lower anchorage and buckle is positioned $160 \mathrm{~mm}$ forward to increase the lap belt angle and reduce submarining tendency. The locking tongue is also added in this case to help reducing the submarining tendency. From the high-speed video, it is observed that the pelvis forward excursion is greater than that in other cases due to insufficient constraint by the lap belt.

In S821, the knee bolster is moved $300 \mathrm{~mm}$ backward to prevent femur forward displacement during the impact. The locking tongue is also used in the test. In this test, no submarining is observed on both sides of the dummy, which verifies the effectiveness of this countermeasure. The combination of the knee bolster and the one-way seatbelt locking tongue can reduce submarining tendency. 
The injury parameters required in FMVSS 208 are listed in Table 5. Since no airbag used in the tests, the Nij exceeds the threshold level required in FMVSS 208 even for the upright seat. It was demonstrated that the neck injury numbers can meet the FMVSS 208 requirement using airbag. Comparing S815 with S816, it can be observed that large seatback angle not only resulted in high submarining risk but also increased the head, neck and chest injury numbers (except the chest compression). This was consistent with the simulation results. Besides, three of four countermeasures could prevent the submarining with no other auxiliary hurts. Below are the suggested countermeasures in this section: (1) anti-submarining bar plus locking tongue; (2) anchor and buckle forward plus locking tongue; (3) knee bolster backward plus locking tongue.

\section{Discussion}

Submarining tendency is very sensitive to the configuration of the restraint system and its dynamic characteristics during frontal impact. It is necessary to have a good understanding of the kinematics of the occupant before and during submarining. Then, it is possible to prevent submarining by controlling the occupant kinematics, which may be achieved by adjusting the existing occupant restraint systems.

Taking the seat as a reference, generally, in frontal impact, the occupant will move forward along with a downward movement relative to the seat due to the combined action of the inertia force and the lap belt force. To facilitate the discussion, two critical points are defined in the side view of the body, the H-point and the S-point in Figure 18. Another symbol $r$ is used to characterise the submarining potential in terms of the kinematics aspect.

Figure 18 Kinematic description of submarining

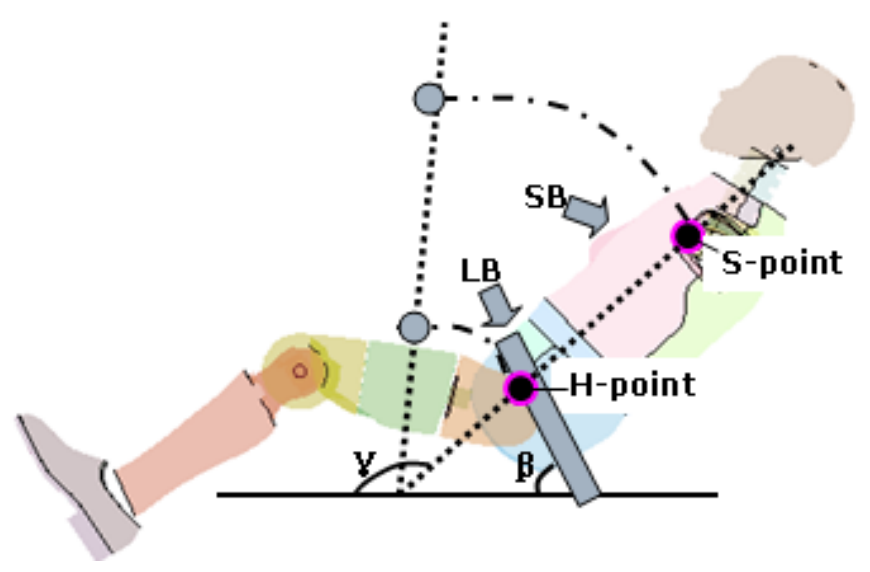

The forward movement of the H-point makes the lap belt more horizontal ( $\beta$ becomes smaller), brings the torso angle $r$ greater, and thus increases the pelvis rearward rotation. But the forward movement of the S-point brings upper torso to rotate forward and results in a smaller $r$. Since the upper torso is connected to the pelvis through the lumbar spine, this movement partly counteracts the pelvis rearward rotation and therefore reduces the 
submarining tendency. In particular, if the forward movement of the S-point is always faster and greater than that of the H-point, the submarining tendency will be reduced. Since the seatback is initially reclined and the torso angle is large, the pelvis is initially at a position where the submarining tendency is greater. By considering these adverse factors, it is important to manage the relative movement tendency between the H-point and the S-point during impact.

Besides the forward movement, the H-point vertical movement is also of concern. First, consider a general case illustrated in Figure 19, where the seat cushion is nearly horizontal. Since the inertia force of frontal impact is almost parallel to the seat cushion, the vertical movement is mainly initiated by the vertical component of the lap belt force, which pushes the pelvis downwards. Larger vertical movement of the H-point to the seat cushion (Hy) indicates greater slip between the belt and the pelvis, and implies higher risk of submarining.

Figure 19 Decomposition of H-point displacement in normal cushion angle

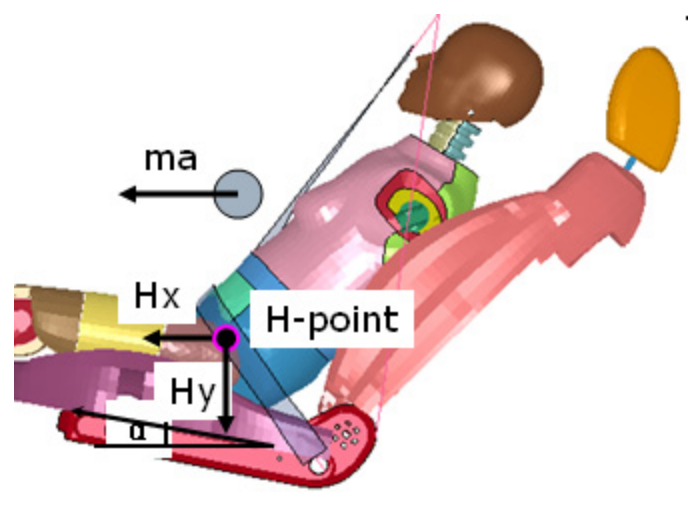

Then, consider the case of a non-zero seat cushion angle $\alpha$ in Figure 20. The H-point displacement is decomposed into two components along and perpendicular to the seat cushion, respectively. Different from the case in Figure 19, the direction of the inertia force and the seat cushion normal are no longer perpendicular. The inertia force has a component vertical to the seat cushion, which produces the movement $(\mathrm{Hv})$ along the direction, as shown in Figure 20(b). In this case, combined with the lap belt force, the inertia effect results in a larger vertical movement to the seat cushion (Hv). However, in the meantime, the tilted seat cushion also provides an additional contribution to resist the forward movement. The actual submarining tendency depends on the competition of these two factors.

Based on the kinematics theory, for preventing submarining, the H-point forward and downward movements play a negative role, while the S-point forward movement plays a positive role. The relative dynamic position between the H-point and the S-point should be managed to achieve a better posture to prevent submarining. 
Figure 20 Decomposition of H-point displacement in tilted cushion angle. (a) The components of H-point displacement (b) Forces on the seat

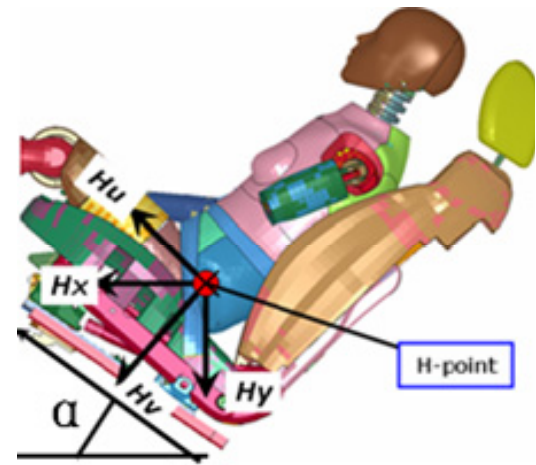

(a)

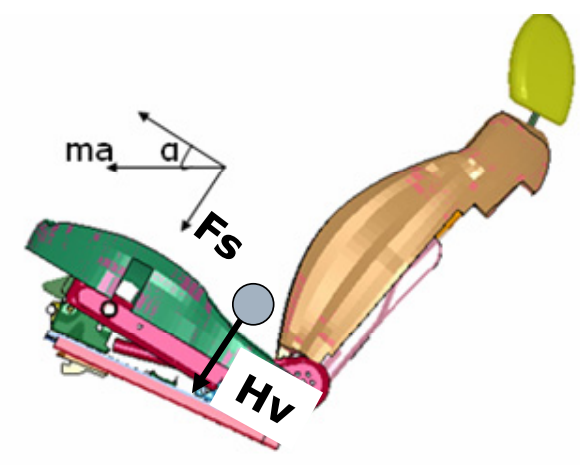

(b)

The shoulder belt effect on submarining tendency may be better understood by considering extreme cases as illustrated in Figure 21. Without the shoulder belt, the kinematics shown in Figure 21(a) indicates that the upper torso rotates forward to a large extent about the lap belt under frontal impact, and submarining does not occur. If both of the lap belt and the shoulder belt are present, and their anchorages are mounted to the seat (all belts to seat), simulations in Figure 21(b) shows that the upper torso cannot rotate forward as it is tightly constrained by the shoulder belt, which greatly increases the submarining tendency. These simulation results demonstrate that the lap belt restraint reduces the submarining tendency, while the shoulder belt restraint increases the tendency. Reducing the shoulder belt restraint force increases the upper torso forward movement, and thus affects the relative position between the S-point and the H-point. In other words, during the impact, if the reclined posture could be changed to a more upright posture, it would help reducing the submarining tendency.

Figure 21 Kinematics simulations of $48 \mathrm{~km} / \mathrm{h}$ impact, seatback angle $50^{\circ}$ and seat cushion angle $10^{\circ}$. (a) Lap belt only (b) All belts to seat

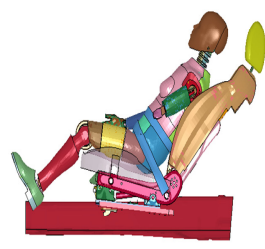

$t=0 \mathrm{~ms}$

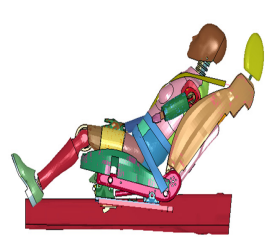

$t=0 \mathrm{~ms}$

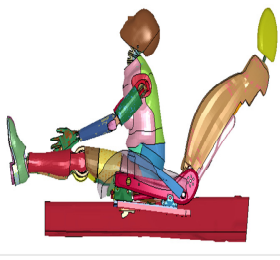

$t=50 \mathrm{~ms}$

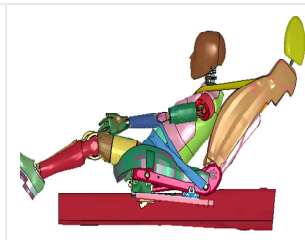

$t=50 \mathrm{~ms}$

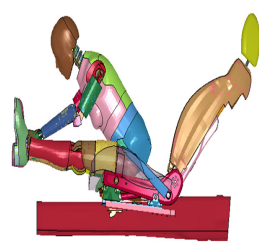

$t=100 \mathrm{~ms}$

(a)

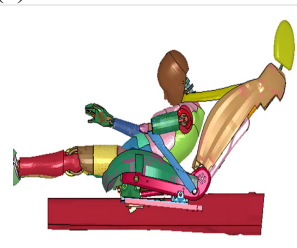

$t=100 \mathrm{~ms}$
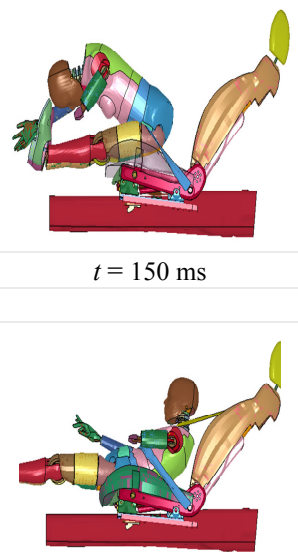

$t=150 \mathrm{~ms}$

(b) 
In summary, submarining is influenced by multiple factors. To prevent submarining, larger lap belt angle with horizontal, smaller pelvis reclining angle and greater belt-topelvis friction are desired. From the viewpoint of initial configuration, methods of reducing submarining tendency include increasing the lap belt angle (e.g., moving forward the lap belt anchor point on the vehicle floor), reducing the seatback angle, and reducing the lap belt slack. From the occupant kinematics aspect, the H-point forward and downward displacements should be reduced and the S-point forward displacement should be increased to guarantee the anti-submarining kinematics. Increasing the axial force applied to the femur (e.g., from the knee bolster or knee airbag), the horizontal seat cushion force and/or the lap belt force can help reducing the H-point forward displacement, which is beneficial to anti-submarining. Reducing the upper torso restraint helps increasing the S-point travel, which reduces the submarining risk. Moreover, appropriate seat cushion stiffness is needed to reduce the H-point vertical movement into the seat cushion and submarining tendency. According to the moment-based theory, to reduce submarining risk, the positive moment for pelvis forward rotation should be increased. To achieve it, it is desirable to reduce the shoulder belt constraint, increase the horizontal resistant force from the seat cushion, and/or increase the lap belt angle.

\section{Concluding remarks}

Using the modified dummy model, a large matrix of parametric study has been carried out to investigate the effects of the submarining factors. The main conclusions and findings are summarised as follows:

1) Greater reclining seatback angle leads to larger pelvis rearward rotation and thus higher submarining risk.

2) Larger lap belt angle implies greater positive moment for pelvis forward rotation and thus smaller submarining tendency.

3) Increasing the belt-to-pelvis friction leads to higher critical belt-to-pelvis angle, and thus smaller submarining tendency.

4) One-way seatbelt locking tongue, preventing the shoulder belt moving into the lap belt while allowing the opposite belt movement, can reduce the lap belt slack and the H-point forward movement and increase the upper torso forward rotation and the S-point forward movement, and thus reduce submarining tendency.

5) Using the load limiter and positioning the D-ring forward can reduce the shoulder belt constraint to the upper torso and allow more forward rotation of the upper torso, and thus reduce submarining tendency.

6) Adding cushion airbag or anti-submarining bar under the seat cushion produces positive moment for the pelvis forward rotation and reduces the H-point downward movement, and thus lower submarining tendency.

7) Knee bolster and knee airbag, producing the femur force acting on the hip joint, can reduce pelvis forward excursion and/or produce the moment for pelvis forward rotation and thus lower submarining risk. 
In conclusion, four suggested countermeasures are proposed for reclining seats to prevent submarining and other injury measurements are within FMVSS208 corridor: (1) load limiter plus locking tongue, (2) anchor pretensioners plus anti-submarining bar, (3) seat cushion airbag, (4) retractor plus buckle pretensioner.

\section{Limitations and future work}

The biofidelity of ATDs should be improved to study submarining, although in this paper the pelvis structure was modified to be more humanlike, there are other biofidelity issues concerned with submarining. The next step is using human model(s) to investigate the effects of vehicle configuration on the submarining tendency of reclining seats. Furthermore, this study demonstrated a conflicting effect between submarining risk and other injury risk. More research is needed to determine how to design the restraint system to reduce occupant submarining without increasing the risk of injuries to other body regions.

\section{Acknowledgement}

We would like to thank General Motors for providing materials and properties of the seat.

This work is financially supported by the National Science Foundation of China under Grant No. 51975057.

\section{References}

Adomeit, D. (1979) 'Seat design - a significant factor for safety belt effectiveness', SAE Transactions, pp.3326-3337.

Adomeit, D. and Heger, A. (1975) 'Motion sequence criteria and design proposals for restraint devices in order to avoid unfavorable biomechanic conditions and submarining', Stapp Car Crash Conference, San Diego, CA.

Baudrit, P., Potier, P., Petit, P., Trosseille, X. and Vallancien, G. (2005) 'Cadaver and dummy investigation of injury risk with anti-sliding system in case of static deployment', Proceedings: International Technical Conference on the Enhanced Safety of Vehicles, Washington, USA.

Beck, B., Brown, J. and Bilston, L.E. (2011) 'Variations in rear seat cushion properties and the effects on submarining', Traffic Injury Prevention, Vol. 12, pp.54-61.

Couturier, S., Faure, J., Satué, R., Huguet, J. and Hordonneau, J. (2007) 'Procedure to assess submarining in frontal impact', 20th International Technical Conference on the Enhanced Safety of Vehicles (ESV) National Highway Traffic Safety Administration, Lyon, France.

Damon, A.M., Lessley, D.J., Salzar, R.S., Bass, C.R., Shen, F.H. and Paskoff, G.R. (2010) 'Kinematic response of the spine during simulated aircraft ejections', Aviation, Space, Environmental Medicine, Vol. 81, pp.453-459.

Dissanaike, S., Kaufman, R., Mack, C.D., Mock, C. and Bulger, E. (2008) 'The effect of reclined seats on mortality in motor vehicle collisions', Journal of Trauma Acute Care Surgery, Vol. 64, pp.614-619. 
Faure, J., Couturier, S., Page, Y. and Labrousse, M. (2007) 'The benefits of double pretension in decreasing knees and lower legs injuries in frontal impacts', Proceedings of the 20th International Technical Conference on the Enhanced Safety of Vehicles (ESV) National Highway Traffic Safety Administration, Lyon, France.

Horsch, J.D. and Hering, W.E. (1989) 'A kinematic analysis of lap-belt submarining for test dummies', Proceedings of the SAE International 33rd Stapp Car Crash Conference, Washington, USA.

Ji, P., Huang, Y. and Zhou, Q. (2017) 'Mechanisms of using knee bolster to control kinematical motion of occupant in reclined posture for lowering injury risk', International Journal of Crashworthiness, Vol. 22, pp.415-424.

Jorlöv, S., Bohman, K. and Larsson, A. (2017) 'Seating positions and activities in highly automated cars - a qualitative study of future automated driving scenarios', Proceedings of the International Research Conference on the Biomechanics of Impact, Antwerp, Belgium.

Laporte, A. (2006) Motor vehicle seat part comprising an anti-submarining crosspiece, United States Patent 6648409.

Leung, Y., Tarriere, C., Fayon, A., Mairesse, P. and Banzet, P. (1981) 'An anti-submarining scale determined from theoretical and experimental studies using three-dimensional geometrical definition of the lap-belt', SAE Transactions, Vol. 90, pp.3232-3253.

Lövsund, P., Nilson, G., Thorngren, L., Håland, Y. and Svensson, S.-E. (1993) 'A test-rig for parametric studies of the car seat', International Congress and Exposition.

Luet, C., Trosseille, X., Drazétic, P., Potier, P. and Vallancien, G. (2012) 'Kinematics and dynamics of the pelvis in the process of submarining using PMHS sled tests', Stapp Car Crash Journal, Vol. 56, pp.411-442.

Lundell, B., Mellander, H. and Carlsson, I. (1981) 'Safety performance of a rear seat belt system with optimized seat cushion design', SAE Technical Paper Series: Passenger Car Meeting and Exposition, vol. 1, pp.2406-2412.

Nakane, K., Nojiri, M., Maekawa, R., Esaki, M., Suzuki, S., Masuda, Y. and Hitosugi, M. (2015) 'Analysis of abdominal injuries caused by the submarining phenomenon in the rear seat occupants', Proceedings of the 24th International Technical Conference on the Enhanced Safety of Vehicles, Gothenburg, Sweden.

O'Connor, C. and Rao, M. (1990) 'Dynamic simulations of belted occupants with submarining', SAE Transactions, pp.1562-1576.

Poplin, G.S., McMurry, T.L., Forman, J.L., Hartka, T., Park, G., Shaw, G., Shin, J., Joo Kim, H. and Crandall, J. (2015) 'Nature and etiology of hollow-organ abdominal injuries in frontal crashes', Accident Analysis Prevention, Vol. 78, pp.51-57.

Pywell, J.F. (1993) 'Automotive seat design affecting comfort and safety', SAE Transactions, Vol. 102, No. 6, pp.142-153.

Richard, O., Uriot, J., Trosseille, X. and Sokolowski, M. (2015) 'Occupant restraint optimisation in frontal crash to mitigate the risk of submarining in out-of-position situation', Proceedings of IRCOBI Conference, Lyon, France.

Richards, D., Carhart, M., Raasch, C., Pierce, J., Steffey, D. and Ostarello, A. (2006) 'Incidence of thoracic and lumbar spine injuries for restrained occupants in frontal collisions', Annual Proceedings/Association for the Advancement of Automotive Medicine, Vol. 50, pp.125-139.

Rouhana, S.W., Horsch, J.D. and Kroell, C.K. (1989) 'Assessment of lap-shoulder belt restraint performance in laboratory testing', Stapp Car Crash Journal, Vol. 33, pp.243-256.

Salzar, R.S., Bolton, J.R., Crandall, J.R., Paskoff, G.R. and Shender, B.S.(2009) 'Ejection injury to the spine in small aviators: sled tests of manikins vs. post mortem specimens', Aviation, Space, Environmental Medicine, Vol. 80, pp.621-628.

Song, D., Mack, P., Tarriere, C., Brun-Cassan, F., Le Coz, J.Y. and Lavaste, F. (1993) 'Finite element simulation of the occupant/belt interaction: chest and pelvis deformation, belt sliding and submarining', Stapp Car Crash Conference, Vol. 1. 
Tang, L. and Liu, J. (2012) 'Safety analysis of belted occupant in reclining seat', International Journal of Vehicle Design, Vol. 60, Nos. 1/2, pp.39-56.

Tang, L. and Zhou, Q. (2009) 'A theoretical study of submarining tendency of a hybrid III 5th percentile female dummy', In Proceedings of ASME International Mechanical Engineering Congress and Exposition, Florida, USA.

Tang, L., Wang, Y. and Zhou, Q. (2010) 'The effect of constrained hip-joint design on crash dummy responses', International Journal of Crashworthiness, Vol. 15, pp.369-376.

Thorbole, C.K. (2015) 'Seatbelt submarining injury and its prevention countermeasures: how a cantilever seat pan structure exacerbate submarining', Journal of Family Medicine Primary Care, Vol. 4, No. 4, pp.587-590.

Uriot, J., Baudrit, P., Potier, P., Trosseille, X., Petit, P., Guillemot, H., Guérin, L. and Vallancien, G. (2006) 'Investigations on the belt-to-pelvis interaction in case of submarining', Stapp Car Crash Journal, Vol. 50, pp.53-73.

Uriot, J., Potier, P., Baudrit, P., Trosseille, X., Petit, P., Richard, O., Compigne, S., Masuda, M. and Douard, R. (2015a) 'Reference PMHS sled tests to assess submarining', Proceedings of the 59th Stapp Car Crash Conference, Vol. 59, pp.203-223.

Uriot, J., Potier, P., Baudrit, P., Trosseille, X., Richard, O. and Douard, R. (2015b) 'Comparison of HII, HIII and THOR dummy responses with respect to PMHS sled tests', Proceedings of IRCOBI Conference, Lyon, France.

Wiechel, J. and Bolte, J. (2006) Response of Reclined Post Mortem Human Subjects to Frontal Impact, SAE technical paper number: 2006-01-0674. 


\section{Appendix}

Animations for the computational simulations in Sub-section 3.2

Case (I) $80 \mathrm{~ms}$ (II) $100 \mathrm{~ms}$


Animations for the computational simulations in Sub-section 3.2 (continued)

\begin{tabular}{|l|l|l|l|}
\hline Case & (I) $80 \mathrm{~ms}$ & (II) $100 \mathrm{~ms}$ & (III) $120 \mathrm{~ms}$ \\
\hline & & &
\end{tabular}

